\title{
PENERAPAN KESELAMATAN PASIEN RUMAH SAKIT
}

\author{
Liza Salawati ${ }^{1}$ \\ ${ }^{1}$ Bagian Ilmu Kesehatan Masyarakat/Ilmu Kedokteran Komunitas Fakultas Kedokteran Universitas Syiah Kuala \\ Corresponding Author : lizasalawati.dr@gmail.com
}

\begin{abstract}
Abstrak
Keselamatan pasien merupakan sebuah prioritas utama yang harus diprogramkan dan dilaksanakan oleh rumah sakit, yang bertujuan untuk melindungi pasien dari setiap kejadian tak terduga yang tak diharapkan. Pada tahun 2000, Institute of Medicine, Amerika Serikat dalam To Err Is Human, Building a Safer Health System melaporkan bahwa dalam pelayanan pasien rawat inap di rumah sakit ada sekitar 3-16\% kejadian tidak diharapkan. Hampir setiap tindakan dan perawatan di rumah sakit berpotensi tinggi untuk terjadinya kesalahan medis seperti kesalahan penentuan diagnosis penyakit, keterlambatan diagnosis, pemeriksaan awal yang tidak sesuai, tidak sesuai observasi, kesalahan pada tahap pengobatan seperti salah memberikan obat, pelaksaan terapi, dan lain lainnya. Pada tahun 2004, World Health Organization (WHO) mencanangkan Safety Is a Fundamental Principle of Patient Care and a Critical Component of Quality Management, program tersebut merupakan program bersama dengan berbagai negara untuk meningkatkan keselamatan pasien di rumah sakit. Berdasarkan hal tersebut rumah sakit harus menerapkan sistim keselamatan pasien.
\end{abstract}

Kata kunci: keselamatan pasien; KTD; rumah sakit

\section{Implementation of Hospital Patients Safety}

\begin{abstract}
Patient safety is a top priority that must be programmed and implemented by the hospital, which aims to protect patients from any unexpected events. In 2000, the Institute of Medicine, United States in "To Err Is Human, Building a Safer Health System" reported that there were about $3-16 \%$ of unexpected events had been occurred within the hospital among inpatients while receiving health services. Almost every action and treatment in the hospital have the potential for the occurrence of medical errors such as misdiagnosis of the disease, late diagnosis, the initial medical examination that is not appropriate, not according to observation, errors in the treatment stage such as wrong medication, the implementation of therapy, and others. In 2004, the World Health Organization (WHO) launched "Safety Is a Fundamental Principle of Patient Care and a Critical Component of Quality Management", the program was a joint program with various countries to improve patient safety in hospitals. According to the document, patient safety system has to be implemented within the hospitals.
\end{abstract}

Keywords: patient safety; AE; hospital 


\section{PENDAHULUAN}

Keselamatan pasien (patient safety) adalah suatu sistem dimana rumah sakit membuat asuhan pasien lebih aman dalam upaya mencegah terjadinya cidera yang disebabkan oleh kesalahan akibat melaksanakan suatu tindakan atau tidak mengambil tindakan yang seharusnya diambil. ${ }^{1}$ Menurut Komite Keselamatan Pasien Rumah Sakit tahun 2008, keselamatan pasien adalah kondisi pasien bebas dari cedera yang tidak seharusnya terjadi yang masih bisa dihindari atau bebas dari risiko dan cidera yang berpotensial akan terjadi. ${ }^{2}$ Berdasarkan Peraturan Menteri Kesehatan Republik Indonesia Nomor 11 Tahun 2017, keselamatan pasien merupakan suatu sistem yang membuat asuhan pasien lebih aman, meliputi asesmen risiko, identifikasi dan pengelolaan risiko pada pasien, pelaporan dan analisis insiden, kemampuan belajar dari insiden dan tindak lanjutnya, serta implementasi solusi untuk meminimalkan timbulnya risiko dan juga mencegah terjadinya cidera yang disebabkan kesalahan akibat melaksanakan suatu tindakan atau tidak mengambil tindakan yang seharusnya diambil. ${ }^{3}$ Berdasarkan laporan KKPRS terdapat 144 insiden (2009), 103 insiden (2010), dan 34 laporan insiden pada triwulan I tahun 2011. Rendahnya insiden di Indonesia oleh karena tidak semua insiden terlaporkan. Umumnya insiden tidak dilaporkan, tidak dicatat, dan juga bahkan luput dari perhatian petugas kesehatan karena yang dilaporkan hanya insiden yang ditemukan secara kebetulan saja. ${ }^{4}$ Beberapa faktor yang mempengaruhi rendahnya laporan insiden yaitu sebagai berikut: 1) Pelaporan insiden masih dipersepsikan sebagai pekerjaan perawat, seharusnya yang membuat laporan tersebut adalah siapa saja atau semua staf yang pertama menemukan kejadian dan yang terlibat dalam insiden, 2) Insiden yang terjadi sering disembunyikan (underreport), insiden dilaporkan namun sering terlambat serta laporan tersebut miskin data, 3) Masih adanya budaya menyalahkan (blame culture) menjadi penyebab terhambatnya pelaporan insiden karena takut disalahkan oleh manajemen dan unit terkait (adanya ketakutan petugas untuk melaporkan), 4) Kurangnya komitmen pimpinan, 5) Kurangnya sosialisasi dan pelatihan pelaporan IKP kepada semua pihak di organisasi, sehingga petugas tidak tahu apa dan bagaimana cara melaporkan ketika insiden terjadi. Pengetahuan memegang peranan penting dalam proses pelaporan IKP, apabila petugas sendiri tidak paham bagaimana sistem pelaporan IKP menyebabkan IKP tidak terlaporkan, 6) Tidak ada reward dari rumah sakit jika melaporkan. 7) Tingginya beban kerja. ${ }^{4}$ Hal tersebut menjadi tantangan semua pihak. Pemerintah dan fasilitas kesehatan bertanggung jawab memastikan sistem pelaporan dapat terlaksana dengan baik. ${ }^{4}$ Tujuan sistim keselamatan pasien adalah sebagai berikut: a) Menciptakan budaya keselamatan pasien di rumah sakit, b) Meningkatkan akuntabilitas rumah sakit terhadap pasien dan masyarakat, c) Menurunkan 
kejadian tidak diharapkan (KTD) di rumah sakit, d) Melakukan pencegahan sehingga tidak akan terjadi kejadian yang tidak diharapkan. ${ }^{5}$

\section{JENIS INSIDEN}

Jenis insiden dapat dibagi sebagai berikut: ${ }^{4}$

a. Kejadian tidak diharapkan (KTD)

Suatu kejadian yang mengakibatkan cedera yang tidak diharapkan pada pasien karena suatu tindakan atau karena tidak bertindak, bukan karena underlying disease atau kondisi pasien.

b. Kejadian nyaris cedera (KNC)

Suatu Insiden yang belum sampai terpapar ke pasien sehingga tidak menyebabkan cedera pada pasien.

c. Kejadian tidak cedera (KTC)

Insiden yang sudah terpapar ke pasien, tetapi tidak menimbulkan cedera, dapat terjadi karena keberuntungan.

d. Kondisi potensial cedera (KPC)

Kondisi yang sangat berpotensi untuk menimbulkan cedera, tetapi belum terjadi insiden.

e. Kejadian sentinel

Suatu KTD yang mengakibatkan kematian atau cedera yang serius.

\section{STANDAR KESELAMATAN PASIEN}

Standar keselamatan pasien rumah sakit di Indonesia mengacu pada Hospital Patient Safety Standard yang dikeluarkan oleh Joint Commmision on Acreditation of Health Organizations Illnois tahun 2002, yang diselaraskan dengan situasi dan kondisi yang terjadi di Indonesia. Standar keselamatan pasien terdiri dari 7 standar yaitu sebagai berikut : $:^{3.5,6}$

\section{a. Hak pasien}

Pasien dan keluarganya mempunyai hak untuk mendapatkan informasi tentang rencana dan hasil pelayanan termasuk kemungkinan terjadinya KTD. Kriterianya adalah sebagai berikut: a) Harus ada dokter penanggung jawab pelayanan, b) Dokter penanggung jawab pelayanan wajib membuat rencana pelayanan, c) Dokter penanggung jawab pelayanan wajib memberikan penjelasan yang jelas dan benar kepada pasien dan keluarga tentang rencana dan hasil pelayanan, pengobatan tau prosedur untuk pasien termasuk kemungkinan terjadinya KTD. 


\section{b. Mendidik pasien dan keluarga}

Rumah sakit harus mendidik pasien dan keluarganya tentang kewajiban dan tanggung jawab pasien dalam asuhan keperawatan. Kriterianya adalah keselamatan dalam pemberian pelayanan dapat ditingkatkan dengan keterlibatan pasien sebagai partner dalam proses pelayanan. Karena itu, di rumah sakit harus ada sistem dan mekanisme mendidik pasien dan keluarganya tentang kewajiban dan tanggung jawab pasien dalam asuhan keperawatan. Dengan pendidikan tersebut diharapkan pasien dan keluarga dapat: a) Memberikan info yang benar, jelas, lengkap dan jujur, b) Mengetahui kewajiban dan tanggung jawab, c) Mengajukan pertanyaan untuk hal yang tidak dimengerti, d) Memahami dan menerima konsekuensi pelayanan, e) Mematuhi instruksi dan menghormati peraturan rumah sakit, f) Memperlihatkan sikap menghormati dan tenggang rasa, g) Memenuhi kewajiban finansial yang disepakati.

\section{c. Keselamatan pasien dan kesinambungan pelayanan}

Rumah sakit menjamin kesinambungan pelayanan dan menjamin koordinasi antar tenaga dan antar unit pelayanan dengan kriteri sebagai berikut: a) Terdapat koordinasi pelayanan secara menyeluruh mulai dari saat pasien masuk, pemeriksaan, diagnosis, perencanaan pelayanan, tindakan pengobatan, rujukan dan saat pasien keluar dari rumah sakit, b) Terdapat koordinasi pelayanan yang disesuaikan dengan kebutuhan pasien dan kelayakan sumber daya secara berkesinambungan sehingga pada seluruh tahap pelayanan transisi antar unit pelayanan dapat berjalan baik dan lancar, c) Terdapat koordinasi pelayanan yang mencakup peningkatan komunikasi untuk memfasilitasi dukungan keluarga, pelayanan keperawatan, pelayanan sosial, konsultasi dan rujukan, pelayanan kesehatan primer dan tindak lanjut lainnya, d) Terdapat komunikasi dan transfer informasi antar profesi kesehatan sehingga dapat tercapainya proses koordinasi tanpa hambatan, aman dan efektif.

\section{d. Penggunaan metode-metode peningkatan kinerja untuk melakukan evaluasi dan program peningkatan keselamatan pasien.}

Rumah sakit harus mendesain proses baru atau memperbaiki proses yang ada, memantau dan mengevaluasi kinerja melalui pengumpulan data, analisis data secara intensif, dan melakukan perubahan untuk meningkatkan kinerja serta keselamatan pasien dengan kriteria berikut : a) Setiap rumah sakit harus melakukan proses perancangan yang baik, sesuai dengan slogan Tujuh langkah menuju keselamatan pasien rumah sakit, b) Setiap rumah sakit harus melakukan pengumpulan data kinerja, c) Setiap rumah sakit harus 
melakukan evaluasi intensif, d) Setiap rumah sakit harus menggunakan semua data dan informasi hasil analisis.

\section{e. Peran kepemimpinan dalam meningkatkan keselamatan pasien}

Peran pimpinan dalam meningkatkan keselamatan pasien adalah sebagai berikut: a) Pimpinan mendorong dan menjamin implementasi program melalui penerapan 7 Langkah Menuju Keselamatan Pasien Rumah Sakit, b) Pimpinan menjamin berlangsungnya program proaktif identifikasi risiko keselamatan pasien dan program mengurangi $\mathrm{KTD}$, c) Pimpinan mendorong dan menumbuhkan komunikasi dan koordinasi antar unit dan individu berkaitan dengan pengambilan keputusan tentang keselamatan pasien, d) Pimpinan mengalokasikan sumber daya yang adekuat untuk mengukur, mengkaji, dan meningkatkan kinerja rumah sakit serta tingkatkan keselamatan pasien, e) Pimpinan mengukur dan mengkaji efektifitas kontribusinya dalam meningkatkan kinerja rumah sakit dan keselamatan pasien, dengan kriteria sebagai berikut:

- Terdapat tim antar disiplin untuk mengelola program keselamatan pasien

- Tersedia program proaktif untuk identifikasi risiko keselamatan dan program meminimalkan insiden, yang mencakup jenis-jenis kejadian yang memerlukan perhatian, mulai dari kejadian nyaris cedera (near miss) sampai dengan KTD ( adverse event)

- Tersedia mekanisme kerja untuk menjamin bahwa semua komponen dari rumah sakit terintegrasi dan berpartisipasi dalam program keselamatan pasien

- Tersedia prosedur cepat-tanggap terhadap insiden, termasuk asuhan kepada pasien yang terkena musibah, membatasi risiko pada orang lain dan penyampaian informasi yang benar dan jelas untuk keperluan analisis

- Tersedia mekanisme pelaporan internal dan eksternal berkaitan dengan insiden termasuk penyediaan informasi yang benar dan jelas tentang analisis akar masalah near miss, KTD dan kejadian sentinel pada saat program keselamatan pasien mulai dilaksanakan

- Tersedia mekanisme untuk menangani berbagai jenis insiden, misalnya menangani kejadian sentinel atau kegiatan proaktif untuk memperkecil risiko, termasuk mekanisme untuk mendukung staf dalam kaitan dengan kejadian sentinel

- Terdapat kolaborasi dan komunikasi terbuka secara sukarela antar unit dan antar pengelola pelayanan di dalam rumah sakit dengan pendekatan antar disiplin 
- Tersedia sumber daya dan sistem informasi yang dibutuhkan kegiatan perbaikan kinerja rumah sakit dan perbaikan keselamatan pasien, termasuk evaluasi berkala terhadap kecukupan sumber daya tersebut

- Tersedia sasaran terukur, dan pengumpulan informasi menggunakan kriteria objektif untuk mengevaluasi efektivitas perbaikan kinerja rumah sakit dan keselamatan pasien, termasuk rencana tindak lanjut dan implementasinya

\section{f. Mendidik staf tentang keselamatan pasien}

Standar mendidik staf tentang keselamatan pasien adalah sebagai berikut: a) Rumah sakit memiliki proses pendidikan, pelatihan dan orientasi untuk setiap jabatan mencakup keterkaitan jabatan dengan keselamatan pasien secara jelas, b) Menyelenggarakan pelatihan tentang kerjasama kelompok (teamwork) guna mendukung pendekatan interdisiplin dan kolaboratif dalam rangka melayani pasien, c) Rumah sakit menyelenggarakan pendidikan dan pelatihan yang berkelanjutan untuk meningkatkan dan memelihara kompetensi staf serta mendukung pendekatan interdisiplin dalam pelayanan pasien, dengan kriteria sebagai berikut:

- Memiliki program diklat dan orientasi bagi staf baru yang memuat topik keselamatan pasien

- Mengintegrasikan topik keselamatan pasien dalam setiap kegiatan inservice training dan memberi pedoman yang jelas tentang pelaporan insiden

\section{g. Komunikasi merupakan kunci bagi staf untuk mencapai keselamatan pasien}

Standar komunikasi merupakan kunci bagi staf untuk mencapai keselamatan pasien adalah sebagai berikut: a) Rumah sakit merencanakan dan mendesain proses manajemen informasi keselamatan pasien untuk memenuhi kebutuhan informasi internal dan eksternal, b) Transmisi data dan informasi harus tepat waktu dan akurat, dengan kriteria sebagai berikut:

- Disediakan anggaran untuk merencanakan dan mendisain proses manajemen untuk memperoleh data dan informasi tentang hal-hal terkait dengan keselamatan pasien

- Tersedia mekanisme identifikasi masalah dan kendala komunikasi untuk merevisi manajemen informasi yang ada 


\section{SASARAN KESELAMATAN PASIEN}

Fasilitas pelayanan kesehatan selain diwajibkan untuk melaksanakan standar keselamatan pasien, juga melakukan perbaikan tertentu dalam keselamatan pasien. Penyusunan sasaran keselamatan pasien mengacu pada Nine Life safing Patient Safety Solution dari WHO tahun 2007 dan Internatonal Patient Safety Goals (IPSGs) dari Joint Commission International $(\mathrm{JCI})^{7,8}$ Di Indonesia secara nasional untuk seluruh fasilitas pelayanan kesehatan diberlakukan Sasaran Keselamatan Pasien Nasional (SKPN), yang terdiri dari: ${ }^{5}$

- SKP 1: Mengidentifikasi pasien dengan benar

- SKP 2: Meningkatkan komunikasi yang efektif

- SKP 3: Meningkatkan keamanan obat-obatan yang harus diwaspadai

- SKP 4: Memastikan lokasi pembedahan yang benar, prosedur yang benar, pembedahan pada pasien yang benar

- SKP 5: Mengurangi risiko infeksi akibat perawatan kesehatan

- SKP 6: Mengurangi risiko cedera pasien akibat terjatuh

\section{PELAPORAN INSIDEN}

Rumah sakit harus melaporkan segera setiap insiden yang terjadi, oleh karena itu rumah sakit harus mempunyai pedoman yang jelas tentang mekanisme pelaporan insiden. Sistem pelaporan insiden meliputi kebijakan, alur pelaporan, formulir pelaporan dan prosedur pelaporan. Format pelaporan insiden keselamatan pasien (IKP) dapat digunakan oleh setiap rumah sakit. Laporan berisi tentang insiden, lokasi, kronologis, waktu dan akibat kejadian, serta analisis akar masalah near miss, KTD, atau kejadian sentinel. ${ }^{3,4}$ Pelaporan IKP dilakukan secara: a) Internal pada atasan langsung, Tim Keselamatan Pasien, dan direksi dan ekternal. Pelaporan secara internal pada atasan langsung, Tim Keselamatan Pasien Rumah Sakit (KPRS), dan direksi, b) Eksternal kepada Komite Keselamatan Pasien Rumah Sakit (KKPRS) dan Perhimpunan Rumah Sakit Indonesia (PERSI). Alur penanganan IKP adalah sebagai berikut: a) Bila terjadi insiden harus segera ditanggani kemudian membuat laporan kepada atasan langsung di unit terjadinya insiden maksimal 2x24 jam, b) Atasan langsung melakukan penentuan dari grading risiko kejadian insiden dan melakukan investigasi sederhana, c) Laporan hasil investigasi dan laporan insiden dilaporkan kepada tim KPRS, d) Tim KPRS membuat laporan dan rekomendasi untuk dilaporkan kepada direksi, e) Laporan hasil investigasi sederhana/ analisis akar masalah/ Root Cause Analysis (RCA) serta rekomedasi dari Tim KPRS/Pimpinan kemudian dikirimkan ke KKPRS (KNKP) melalui e-reporting menggunakan anonim melalui website resmi www.buk.depkes.go.id ${ }^{3,4,5}$ 


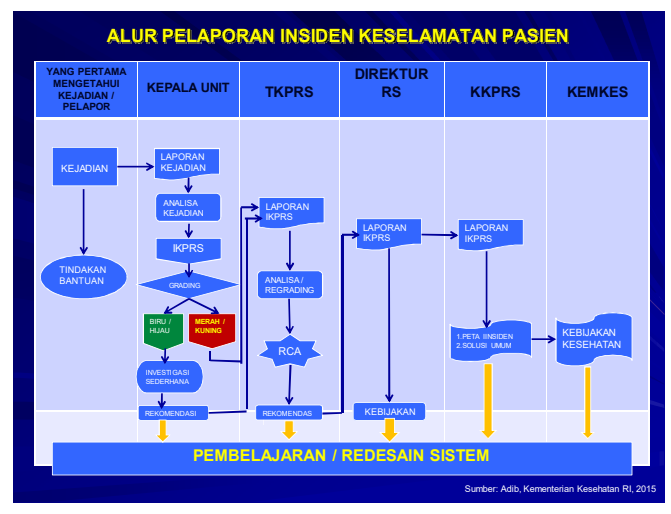

Gambar 1 Alur Pelaporan Insiden Keselamatan Pasien ${ }^{4}$

Faktor organisasi berperan dalam membangun budaya pelaporan sehingga perlu pendekatan organisasi untuk dapat membudayakan segera melapor ketika terjadi insiden. Dengan diterapkannya sistem pelaporan yang baik akan mengajak semua pihak peduli akan bahaya maupun potensi bahaya yang dapat terjadi pada pasien. Niat untuk melaporkan IKP dipengaruhi oleh faktor organisasi dan faktor individu sehingga manajemen dan Tim KPRS perlu melakukan pendekatan secara individu dan organisasi untuk meningkatkan pelaporan IKP. Beberapa upaya yang dapat dilakukan antara lain menciptakan budaya keselamatan pasien dan no blaming, membuat sistem pelaporan yang baik dan mudah dipahami oleh semua pihak, melakukan sosialisasi dan juga pelatihan secara berkala untuk meningkatkan pengetahuan tentang pelaporan IKP, menghilangkan ketakutan terhadap dampak pelaporan, pelaporan secara anonym serta pemberian reward jika melaporkan maupun hukuman yang diambil tidak bersifat blaming maupun hukuman individu. Pentingnya pelaporan insiden karena akan menjadi awal proses pembelajaran untuk mencegah kejadian yang sama terjadi kembali. ${ }^{3,4}$ Data laporan IKP yang akurat sangat bermanfaat untuk menurunkan insiden dan meningkatkan mutu pelayanan dan keselamatan pasien. Dengan adanya data tersebut juga dapat digunakan untuk melakukan pemetaan keselamatan pasien, sebagai dasar perbaikan sistem pelayanan yang berorientasi pada keselamatan pasien dan pencegahan terjadinya IKP berulang serta dapat digunakan oleh semua pihak sebagai pembelajaran dan tidak untuk menyalahkan orang (non blaming). ${ }^{4}$

\section{PELAKSANAAN KESELAMATAN PASIEN}

Pelaksanaan sistim keselamatan pasien adalah sebagai berikut: ${ }^{3,4,9}$

\section{a. Di Pusat}


- Membentuk Komite Keselamatan Pasien Rumah Sakit dibawah Perhimpunan Rumah Sakit Seluruh Indonesia.

- Menyusun panduan nasional tentang Keselamatan Pasien Rumah Sakit.

- Melakukan sosialisasi dan advokasi program keselamatan pasien ke Dinas Kesehatan Propinsi/Kabupaten/Kota, PERSI Daerah dan rumah sakit pendidikan dengan jejaring pendidikan

- Mengembangkan laboratorium uji coba program keselamatan pasien

\section{b. Di Propinsi/Kabupaten/kota}

- Melakukan advokasi program keselamatan pasien ke rumah sakit di wilayahnya

- Melakukan advokasi ke pemerintah daerah agar tersedianya dukungan anggaran terkait dengan program keselamatan pasien rumah sakit

- Melakukan pembinaan pelaksanaan program keselamatan pasien rumah sakit

\section{c. Di Rumah Sakit}

- Rumah sakit agar membentuk Tim KPRS, dengan susunan organisasi sebagai berikut : Ketua : dokter, Anggota : dokter, dokter gigi, perawat, tenaga kefarmasian dan tenaga kesehatan lainnya

- Rumah sakit agar mengembangkan sistem informasi pencatatan dan pelaporan internal tentang insiden

- Rumah sakit agar melakukan pelaporan insiden ke Komite Keselamatan Pasien Rumah Sakit (KKPRS) secara rahasia

- Rumah sakit agar memenuhi standar keselamatan pasien rumah sakit dan menerapkan tujuh langkah menuju keselamatan pasien rumah sakit

- Rumah sakit pendidikan mengembangkan standar pelayanan medis berdasarkan hasil dari analisis akar masalah dan sebagai tempat pelatihan standar-standar yang baru dikembangkan

\section{PENUTUP}

Sistem keselamatan pasien merupakan prioritas utama yang harus dilaksanakan oleh rumah sakit, hal ini sangat erat kaitannya baik dengan citra rumah sakit maupun keselamatan pasien. Oleh karena itu setiap rumah sakit harus menerapkan 7 standar keselamatan pasien untuk melindungi pasien dari kejadian yang tidak diharapkan. 


\section{REFERENSI}

1. Menkes, R.I., Buku Panduan Nasional Keselamatan Pasien Rumah Sakit (Patient Safety). Jakarta: Depkes, R.I., 2008.

2. KKPRS. Pedoman Pelaporan Insiden Keselamatan Pasien (IKP). Edisi 2. Jakarta: KKPRS, 2008.

3. Menkes, R. I., Peraturan Menteri Kesehatan Republik Indonesia Nomor 11 Tahun 2017. Tentang Keselamatan Pasien Rumah Sakit. Jakarta: Menkes, R.I., 2017.

4. KKPRS. Pedoman Pelaporan Insiden Keselamatan Pasien (IKP). Jakarta: KKPRS, 2015.

5. Menkes, R.I., Peraturan Menteri Kesehatan Republik Indonesia Nomor 1691/Menkes/Per/VIII/2011. Tentang Keselamatan Pasien Rumah Sakit. Jakarta:. Kemenkes, R.I, 2011.

6. Joint Commmision on Acreditation of Health Organizations Illnois. Hospital Patient Safety Standard. USA; 2002.

7. WHO. Nine Life Saving Patient Safety Solutions. Collaborating Centre for Patient Safety; 2007. https://www.who.int/patientsafety/solutions/patientsafety/Preamble.pdf

8. Joint Commission International. Internatonal Patient Safety Goals (IPSGs). JCI. https://www.jointcommissioninternational.org/improve/international-patient-safety-goals/

9. Kemenkes, R.I., Pedoman Keselamatan Pasien Rumah Sakit (Patient Safety). Utamakan Keselamatan Pasien. Edisi 3. Jakarta: Direktur Bina Upaya Kesehatan Rujukan, 2015. 